anaemia, various unrelated painful conditions of the lower limbs, chronic pulmonary diseases (Dr. Spillane's cases), uraemia, gastric surgery, and diabetes mellitus. ${ }^{4}$

The following case illustrates the adverse influence of pregnancy. During the later stages of each of her four pregnancies this patient experienced frequently recurring "heavy ache" in the limbs, followed by "spontaneous jerking." The affection involved all four limbs and rendered sleep virtually impossible. When seen some ten years later she reported that she had remained free from these symptoms. These are intensifying influences rather than precipitating factors, since an inquiry will often reveal past episodes of "dyslysis" of minor degree of severity. There may well be an element common to all these divers inf'uences. The disorder can also be "acquired" in multiple sclerosis and Parkinsonism. Anaemia is perhaps the most powerful intensifying factor. Because correction of anaemia - for example, in menorrhagia-will often relieve "dyslysis" completely, it should always be borne in mind in the management of these cases. Reference must also be made to the absence of seizure patterns in the electroencephalogram concurrent with "nocturnal" myoclonus, yet there is little doubt that anticonvulsants, including diazepam, are effective in the treatment of this complaint, which, as Dr. Spillane says, can be of "tormenting nature."-I am, etc.,

London $\mathbf{W} .1$

SIMON BEHRMAN

1 Behrman, S., British Medical fournal, 1958, 1, 2 Willis, T

illis, T., Quoted by Banerii, N. K., and Hur-
witz, L. J., British Medical Ұournal, 1970, 4, Callaghan, N., Neurology (Minneapolis), 1966, 16, Banerii, N. K., and Hurwitz, L. J. British Medical
fournal, 1970, 4, 774.

\section{Medical Management of}

Rheumatoid Arthritis

SIR,-Dr. R. Bluestone's article on the medical management of rheumatoid arthritis (5 December, p. 602) prompts us to take issue with him on several points. We feel well qualified to offer an alternative view because we spend a good deal of time trying to salvage something from the wreckage of joints which orthodox laissezfaire treatment too often leaves behind.

It is futile to treat severe progressive disease with weak, so-called anti-inflammatory agents, which in effect are glorified analgesics. We believe it is wrong to follow the usual sequential method in such cases, since by the time the physician has applied various drugs in turn and found them inadequate irreparable damage has been done to the joints. All too often the space of 18 months witnesses the change from normality to crippling. Perhaps $10 \%$ of patients with seropositive arthritis are in this category. The time is short; their urgent need is for treatment which will be effective with the least possible delay. Aspirin in full dosage, phenylbutazone, indomethacin, and other analgesics are worse than useless in this situation; they ensure only a more comfortable ride to destruction. Only steroids can influence the disease quickly enough to affect the outcome, and the early addition of immunosuppressives may often be advisable.

The use of intra-articular injections of steroids into weight-bearing joints in ambulant patients is often unhelpful if the disease in general is active, and it may increase the risk of joint damage by removing the protection of pain. To describe this as the mose useful role of steroids in rheumatoid disease is short sighted.

The side effects of corticosteroid treatment in small to moderate dosage are less to be feared than the side effects of unrestrained disease; except for pituitary-adrenal inhibition most can be controlled by strict attention to various simple, if tedious, precautions. The toxic effects of chloroquine are less frequently disastrous than $\mathrm{Dr}$ Bluestone thinks, provided that the dosage is moderate and the treatment intermittent. There is evidence that retinal damage may be prevented by protection from ultraviolet light (a minor problem in this country) Moreover, the published reports of controlled trials have not advocated high-dose chloroquine therapy. We agree that gold is often useful and effective, but Dr. Bluestone should remember the limitations as well as the advantages of chrysotherapy; these were clearly defined in the report on the Empire Rheumatism Council trial, ${ }^{1}$ which showed that, in common with antimalarials, gold (under the conditions of the trial) did not influence progression of erosions seen radiologically.

It is crucial that patients should be stratified according to their individual prognosis at an early stage and that appropriate treatment should be given without waiting for gross joint destruction to become evident. It is also desirable that the policy for each patient should be reviewed at regular intervals and that a policy which is failing should be changed.-We are, etc.,

A. J. POPERT B. L. Coulton

Highfield Hospital,

roitwich, Worcs Empire Rheumatism Council Annals of the
Rheumatic Diseases, 1961, 20, 315.

\section{Selective Vagotomy without Drainage}

SIR,-Fifteen months ago I reported the early results of bilateral selective vagotomy without drainage (20 September, 1969, p. 690). The omission of any drainage operation was based on the hypothesis that if truncal vagotomy made a drainage operation obligatory bilateral selective vagotomy, by preserving innervation of the pylorus and duodenal bulb, might allow good gastric emptying without any drainage procedure.

A special food-barium meal was used to study gastric emptying, a film being taken at nine hours and the degree of retention expressed by the size of the barium residue as $0,+,++$ and +++ (see 1969 paper). When the special meal was given to 15 "normal" people 13 were graded 0 and two graded + . The results obtained in 1969 in 17 patients after vagotomy and a single layer Heineke-Mikulicz pyloroplasty are shown in Table I.

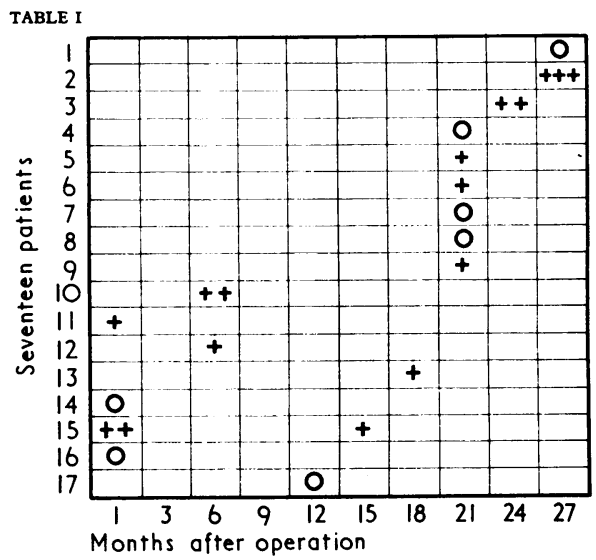

Twenty unselected patients have now been examined one year after bilateral selective vagotomy without drainage. Care was taken to exclude any patients for this operation in whom any degree of organic duodenal narrowing was present. The results (Table II) show that one year after bilateral selective vagotomy without drainage in patients with duodenal ulceration but without organic stenosis gastric emptying is virtually normal. Indeed the stomach empties better without drainage than it does with pyloroplasty. The drainage operation should wherever possible be omitted for there is wide agreement that most of the sequelae of selective vagotomy and drainage are due to the pyloroplasty or gastro-jejunostomy and not to the vagotomy itself.

Some 120 patients have now been treated in this way since April 1967. Not one case has developed lesser curve gastric ulceration. Our studies suggest that when selective vagotomy is used without drainage care must be taken to exclude organic narrowing for mucosal stenosis may be more severe than the muscular narrowing of the duodenum suggests. In some cases the duodenum must be dissected free from adhesions before the muscular narrowing can be seen.

The pyloric branches of the hepatic plexus supply, as Latarjet showed, the pylorus and the duodenal bulb and probably too a very small amount of prepyloric stomach. He stated that the nerves, which we now know by his name, do not reach the pylorus and this fact can be clearly demonstrated in man at operation. Presumably, therefore, the immediate prepyloric stomach is supplied by the pyloric branches from the hepatic plexus. These pyloric branches may be easily stimulated in man. Care must be taken to see that no anti-cholinergic drugs have been previously given. The pylorus and duodenal bulb are seen to contract when the stimulus is applied. If a clamp is placed across the duodenum beyond the bulb, the motor function of these pyloric branches may be demonstrated by a rise in intragastric pressure on stimulation. It seems that bilateral selective vagotomy without drainage is an important step in the evolution of vagotomy. It should encourage us to operate before organic narrowing has occurred.

We now await with interest the late results of highly selective vagotomy without drainage. ${ }^{1-3}$ This important modification is yet another step forward in vagotomy. Already we may claim almost without doubt that highly selective vagotomy without drainage is not followed by recurrent duodenal ulceration nor by gastric ulceration 


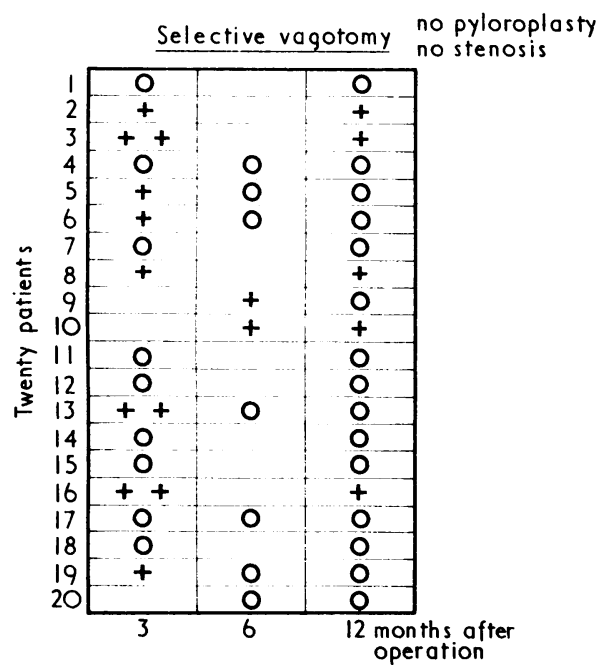

so long as nerve section is complete and the nerves of Latarjet properly preserved. It is a very much better operation than bilateral selective vagotomy without drainage for it can be used in the presence of organic duodenal narrowing. Probably only in advanced duodenal stenosis is a drainage operation required.-I am, etc.,

Harold Burge

Charing Cross Group of Hospitals, West London Hospital,

1 Amdrup, E., Amdrup Bente, M., and Griffith, Amdrup, E., Amdrup Bente, M., and Griffith,
C. A. Fourth World Congress of Gastroentero
logy. Advance Abstracts, P. 430. Griffith, C. A., and 1957 . 32,96 .

3 Johnston, D., Humphrey, C. S., and Wilkinson A. R, Proceedings of Association of Surgeons
of Great Britain and Ireland, 1970.

\section{Controlling Gastric Acid}

SrR,-Your leader "Controlling Gastric Acid" (28 November, p. 510) states "Anticholinergic drugs act by reducing vagal activity. They are fully effective only when given in doses which cause undesirable side effects such as drowsiness, dryness of the mouth blurring of vision, and difficulty with emptying the bladder." All this is true when these drugs are given in single doses. But when they are given four times a day, in the maximal dose that gives no side effects as determined by gradual escalation, the result is different. For example, Mitchell $e$ $a l .{ }^{1}$ compared the reduction of acidity of the gastric contents obtained with atropine or poldine at doses that produced no side effects. The study was double blind, and the mean duration of the treatment was seven days with each drug given four times daily. The mean reduction in acidity of the gastric contents after ordinary food was $60 \%$ with atropine and about $80 \%$ or more with poldine.

Seidelin ${ }^{2}$ studied gastric secretion of acid with doses of poldine that produced no side effects. Using the augmented histamine test he found a reduction of gastric secretion of acid by $50 \%$ after the patients had been treated for about three weeks. He pointed out that the reduction was close to that achieved with the augmented histamine test after vagotomy and gastroenterostomy. Hunt and Douthwaite ${ }^{3}$ gave poldine four times a day at doses which gave no side effects; gastric secretion in response to test meals was reduced by half. These authors also noted that the full effect of poldine took up to three weeks to develop on continuous dosage.

Whether or not poldine is clinically effective is a matter of opinion." However, it does seem to be established that at doses adjusted to the patient a reduction of gastric secretion of acid by $50 \%$-nearly equal to that produced by surgical vagotomy-is commonly obtained without side effects. Moreover, increasing the dose to that which gives side effects does not in our experience reduce gastric secretion further

There is a substantial body of clinical opinion in favour of anticholinergic drugs such as poldine, if these are used properly. While argument continues about the scientific evidence it is unreasonable to assume that experienced clinicians are necessarily mistaking the placebo effect for pharmacological active, particularly as there are good theoretical reasons for expecting anticholinergic drugs to benefit these patients.-We are, etc., Department of Physiology,
Guy' Hospital Medical School,
London S.E.1

J. N. HuNT

Lewisham General Hospital,
London S.E.13

T. M. L. Price

1 Mitchell, R. D., Hunt, J. N., and Grossman, M. I. Gastroenterolory, 1962, 43, 400 .

2 Seidelin, R., British Medical fournal, 1961, 1, 1079. Medical fournal, 1958, 1. 1030 . J. N., British Medical fournal, 1958, 1. 1030.
Hunt, J. N., and Price, T. M. L., Practitioner 1967, 198, 156.

SIR,-With reference to your recent leading article entitled "Controlling Gastric Acid" (28 November, p. 510) we have studied the effect of an inhibitor of histamine synthesis (NSD 1055, Smith and Nephew) on canine gastric acid secreted from total gastric and Pavlov pouches. In several short-term and long-term experiments, NSD 1055 (25 mg and $100 \mathrm{mg} / \mathrm{kg}$ body weight) was administered and acid secreted in response to submaximal doses of bethanecol and pentagastrin was measured. Up to date we have been unable to demonstrate any reduction in acid output. Details of this work will be found in a paper which is now being prepared for publication.-We are, etc.,

GeORGe Dickson Crawford W. Jamieson

Surgical Unit,
St. Mary's Hospital,

London $W .2$

\section{Management of Cancer}

SIR,-Public criticism of the lack of acceptance by the medical profession of apparently encouraging responses from the Bavarian clinic of Dr. Joseph Issels is natural as a first reaction. Now that the mysterious cloak has been removed it appears that of a "random" sample of one-third of 750 cases, only a further one-third, or 88 cases, meet the requirements of accurate analysis. Of these, only $18 \%$ (16 cases) were alive at 5 years (26 December, p. 760 ).

It is now, surely, the important duty of every doctor to give information to anxious relatives and to explain what orthodox medicine can do. In a completely unselected series of patients with very advanced and recurrent breast cancer hormone control $^{1}$ alone produced an objective remission in over $60 \%$ of all patients at 6 months and $50 \%$ at 1 year. With additional treatment a further half of this group without visceral metastases (one-quarter of all such cases) were living at 5 years. There is now a whole list of types of cancer with 5-year survivals, many of which were deadly to the last generation: these include $64 \%$ of liposarcomas ${ }^{2} ; 85 \%$ or more of patients with cancer of the body of the uterus ${ }^{34}$ when efficiently treated by intracavity radiation are usually free of active growth at operation, and even advanced cases do relatively well; $95 \%$ of patients with seminoma of the testis, which is supremely radiosensitive, are alive at this time. ${ }^{5}$ Advances in the treatment of malignant melanoma have produced a survival rate comparable with breast cancer-excellent in the early and far from hopeless in the advanced.

Every clinic dealing with much malignant disease has proved star cases; good examples are:

(1) 20 years' survival from metastatic bone disease in the pelvis from the breast. Some treatment has been given in the meantime but the patient is well and doing a full-time job (androgens and radiotherapy).

(2) 15 years' survival from substantial metastatic disease in bone from a recurrent thyroid cancer in the neck. This patient has just retired from an arduous full-time job and is very well (radiotherapy and thyroxine).

(3) 15 years' survival from true Hodgkin's disease, first in the neck and then five years later forming a large mass in the left groin. Now normal (radiotherapy alone)

The question is, how often can these star cases be produced? After discussion with several of my colleagues of considerable experience, the figure has been put as high as $10 \%$. Surely this is a triumph for British medicine in dealing with such advanced cases? The next question is what methods are employed in obtaining these star results, because they do not come easily. These methods include the following:

(1) Preliminary chemotherapy by intra-arterial infusion combined with the use of an isotopetimed neutralizer to spare the bone marrow and the immune state (for example, nitrogen mustard locally and thiosulphate intravenously).

(2) Chemotherapy as a preliminary to radiation $^{6}$ to render the neoplasm more vascular and smaller-and so more curable. Both, or either, of these methods may be combined with raising the oxygen concentration, either using a hyperbaric tank or giving a drip of dilute hydrogen peroxide.

(3) Surgical procedures may utilize local chemotherapy to prevent recurrence, or employ electrocoagulation destruction if complete excision should prove difficult.

(4) The use of "split course" irradiation, to take advantage of the improved vascularity during treatment and the employment of more accurate and improved methods of irradiation,? so lessening the immunological damage. 8

(5) In widely disseminated or highly undifferentiated tumours, or both, the use of systemic chemotherapy - for example, in chorionepithelioma ${ }^{9}$ or seminoma-and, as a preliminary to immunotherapy-for example, with Corynebacterium parvum vaccination.

(6) Immunotherapy by the local application of smallpox vaccine or systemically by intravenous T.A.B. with subsequent pyrexia

(7) Careful attention to the general condition -blood transfusion; correction of metabolic defects; graduated excercises; and, most important of all, hope and encouragement.

Lastly, the vital decision is when to do 